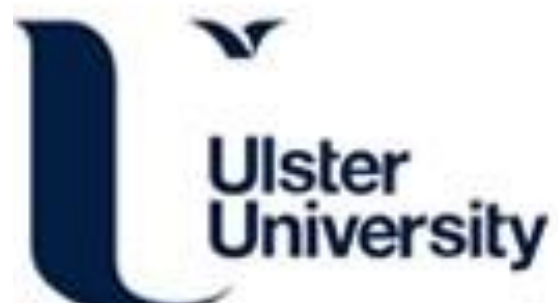

\section{The Value of Including People with Dementia in the Co-Design of Personalized eHealth Technologies}

Leorin, C., Stella, E., Nugent, CD., Cleland, I., \& Paggetti, C. (2019). The Value of Including People with

Dementia in the Co-Design of Personalized eHealth Technologies. Dementia and Geriatric Cognitive Disorders, 47(3), 164-175. https://doi.org/10.1159/000497804

Link to publication record in Ulster University Research Portal

\section{Published in:}

Dementia and Geriatric Cognitive Disorders

Publication Status:

Published (in print/issue): 01/07/2019

DOI:

$10.1159 / 000497804$

\section{Document Version}

Author Accepted version

\section{General rights}

Copyright for the publications made accessible via Ulster University's Research Portal is retained by the author(s) and / or other copyright owners and it is a condition of accessing these publications that users recognise and abide by the legal requirements associated with these rights.

\section{Take down policy}

The Research Portal is Ulster University's institutional repository that provides access to Ulster's research outputs. Every effort has been made to ensure that content in the Research Portal does not infringe any person's rights, or applicable UK laws. If you discover content in the Research Portal that you believe breaches copyright or violates any law, please contact pure-support@ulster.ac.uk. 


\title{
The value of including people with dementia in the co-design of personalized eHealth technologies
}

Cristian Leorin $^{1}$, Eloisa Stella ${ }^{1}$, Christopher Nugent ${ }^{2}$, Ian Cleland ${ }^{2}$, Cristiano Paggetti $^{3}$

\author{
${ }^{1}$ Associazione Novilunio Onlus, Padua, Italy \\ ${ }^{2}$ Ulster University, Computer Science Research Institute, Belfast, Northern Ireland \\ ${ }^{3}$ I + SRL, Florence, Italy
}

Short Title: Co-design with people with dementia

*Corresponding Author

Full name: Cristian Leorin, President

Associazione Novilunio Onlus

Viale Svezia, 16

35020 Ponte San Nicolò, Padua, Italy

Tel: 3282133412

E-mail: cristian.leorin@novilunio.net

Keywords: co-design, co-creation, dementia, eHealth, mHealth, participatory design, patient engagement, person-centered 


\section{Abstract}

Background: In this article, we discuss the benefits and implications of the shift from a user-centered to a co-creation approach in the processes of designing and developing eHealth and mHealth solutions for people with dementia. To this end, we illustrate the case study of a participatory design experience, implemented at the REMIND project, Connected Health Summer School which took place in June 2018 at Artimino (Italy).

Objectives: The initiative was intended to reach two objectives: 1) Help researchers specializing in a variety of fields (engineering, computing, psychology, nursing and dementia care) develop a deeper understanding of how individuals living with dementia expect to be supported and/or enabled by eHealth and mHealth technologies; 2 ) Prevent the tendency to focus on the impairments that characterize dementia at the expense of seeing the individual living with this condition as a whole person, striving to maintain a life that is as fulfilling as possible.

Method: The Connected Health Summer School is an annual multi-disciplinary training program, organized in collaboration with the REMIND EU Project, designed for early stage researchers interested in the development of new eHealth and mHealth services and apps. For the 2018 program edition, REMIND end-users partner, Novilunio, invited two members of the Irish Dementia Working Group to deliver keynote lectures, and engage in participatory workshops to facilitate the creation of digital technology applications based on their specific real-life needs, values, and expectations. Their involvement as subjects and experts was aimed to give a clear message to early stage researchers: a true personalized approach to eHealth and mHealth solutions can only emerge from a highly reflective and immersive appreciation of people's subjective accounts of their lived experience.

Results: The Connected Health Summer School early stage researchers developed 6 app mockups based on their discussions and co-creation activities with the two experts with dementia. Reflections on this experience highlight a number of important issues that demand consideration when undertaking eHealth and mHealth research, co-design and development with and for people with dementia. The evolution in design research from a user-centered approach to co-designing should pave the way to the development of technologies that do not disempower nor reinforce stigma, but instead provide a reliable support to living a life as active and meaningful as possible after a diagnosis of dementia. To this end, the motto of the peak global organization of people with dementia, Dementia Alliance International, says it all: "See the person and not the dementia".

For the accepted length (word count: 2500), if applicable, or journal-specific variations, consult the specific Author Guidelines. 


\section{Introduction}

Although stigma and low levels of understanding of dementia have led most people to believe that a diagnosis of this condition prevents an individual from providing a meaningful contribution to cocreation projects, an increasing number of organizations across the world are now actively engaging people with dementia in disruptive and valuable activities to develop a wide variety of new services and products. This shift reflects the need to create more relevant and effective solutions that result from a deeper and more respectful appreciation of the actual life experience, values and expectations of people living with dementia for which they are intended ${ }^{1,2,3,4}$.

For the purpose of this article, we refer to the term "co-design" in the broader sense indicated by Sanders and Snappers ${ }^{5,6}$ in which the creativity of a variety of individuals, including those not trained in design, is brought together in the development process. In the 'traditional' user-centered design approach, only certain professionals (i.e. the designer, the engineer, the researcher and the physician) are recognized as having the power and expertise to conceive of and give shape to products and services on behalf of "users". Users are often considered as passive objects of study through observation, surveys and interviews ${ }^{7,8,9,10,11}$. In contrast, in the co-design approach the person who will eventually be the recipient of such products or services is given the position of 'expert of his/her experience' and plays a large role in knowledge development, idea generation and concept development ${ }^{5}$.

Co-design forces designers to confront the reality of the experience of the person who will receive the product or service at hand. It is a collaborative approach that promotes a shared understanding based on reflection and dialogue where all parties involved work together as equal towards a shared goal ${ }^{12,13}$.

Although co-design has already proven to be effective and beneficial in several areas of health and technology applications, the involvement of people living with dementia in co-creation and co-design activities is still a relatively new and underdeveloped area of practice. Moreover, products and services developed for people with dementia have so far prevalently focused too much on their impairments and loss of ability and not enough on how they expect to be supported and empowered in light of their individual resources, values and life priorities ${ }^{14,15,16}$. Yet, people with dementia are not just the sum of their acquired impairments ${ }^{17}$. Like the rest of us, they too want to be seen as whole individuals, striving to live a life as good and meaningful as possible, in spite of their condition. This is a view of the person with the dementia that was first introduced by Kitwood's person-centered approach ${ }^{18,19}$, and later further expanded by other researchers who have proposed to include people living with this condition more fully as equal partners in shaping dementia care ${ }^{20}$.

More recently, local and international advocacy groups of people with dementia have further addressed the right to be involved in any process aimed at creating any kind of new service, product or activity for them. Following the disability motto movement "Nothing about us without us," these groups advocate that people with dementia's opinions and perspectives are fundamental when it comes to deciding what they need and expect to live as well as possible with their condition as citizens in the communities where they live $e^{21,22,23,24,25}$.

The 2018 edition of the Connected Health Summer School was conceived to further advance the idea that the involvement of people with dementia since the very early stages of the design process is not only a more ethical approach to creating new eHealth and mHealth technologies, but it is also a powerful framework that is more likely to produce more relevant and effective solutions to everyday problems experienced by those living with this condition. To this end, we involved two advocates with dementia who were diagnosed in their early 50s as keynote speakers and workshop leaders. This was intended to provide a more balanced and realistic appreciation of what it means to endure the impact of an illness that is often misunderstood or mistreated, even by those who are supposed to "know best." This paper describes the Summer School as a model for co-creating with people living with dementia. 


\section{Materials and Methods}

The Connected Health Summer school is an annual intensive learning programme specifically designed to train early stage researchers, including PhD students, postdoctoral fellows (within 3 years of graduating) and researchers with fewer than 5 years' experience following undergraduate study, interested in development, evaluation and commercialization of eHealth and mHealth technology solutions.

The school's learning method is based on a blended approach of traditional didactic teaching experience and participatory workshops intended to help students gain not only the latest advancements in eHealth and mHealth challenges and opportunities, but also have the time and space to explore, reflect and refine their understanding on how technology can improve the lives and care of people with a variety of conditions and disabilities.

The School's 2018 edition focused on "Mobile Health to support people with Dementia and their Caregivers" and delivered content across 4 themes: Technology/ Data Analytics; Health and Social Sciences; Service deployment; Business Innovation. This content was delivered across 4 days - See figure 1 for the full program of the week.

[Figure 1]

In addition to the four identified theme contents, students were assigned into groups of four facilitated by a Tutor. The group work aimed to give students the experience of working in multidisciplinary teams and come up with an innovative solution that addressed a global healthcare challenge related to dementia. Students were assigned based on their academic and/or professional expertise. Each team was created to ensure a good mix of technical and social science backgrounds.

The 2018 Summer School opened with two lectures given by keynote speakers, Ronan Smith (Chair of the Irish Working Group of People with Dementia) and Kathy Ryan (Vice-Chair of the Irish Working Group of People with Dementia) who introduced their audience to their life experience with early onset Alzheimer's disease and how their use of technologies has changed since being diagnosed. Their participation was intended to help students acknowledge the gap between what they thought they knew about dementia and what it means, from direct experience, to live day in and day out with the variety of impacts of this condition.

During this process, students were able to work in a shortened feedback loop with the two experts with dementia and use the initial information collected in the first workshop as baseline that was progressively refined in sketched out mockups. This iterative design approach was especially helpful for people with dementia as it tends to reduce the need for abstract thinking, which may be challenging for individuals with cognitive impairments, and at the same time provide more valuable time and space for in-depth exploration of all participants' opinions and expectations ${ }^{14}$.

\section{Results}

Following the completion of the Summer School, students were asked to complete a short questionnaire to assess the impact of their learning experience and gather feedback on what aspects worked well and what needed to be improved. Twenty students from eight Countries (Ireland, Colombia, Netherlands, Sweden, United Kingdom, Italy, Spain and the Republic of Korea) provided the feedback included in this section.

When asked "How likely is it that you would recommend the Summer School to the colleague?", the Net Promotor Score used to measure the willingness of customers to recommend an event or service, recorded $87 \%$ of appreciation, showing the majority of attendees were likely to recommend the summer school to a colleague.

[Fig. 2] 
In assessing the impact of the Summer School on their future careers, all respondents answered that the experience would have some $(26.67 \%)$ or high impact $(73.33 \%)$ on their career. Assessing how helpful the content presented at the summer school was to their research, respondents answered "Extremely helpful" (20.00\%), "Very Helpful" (73.33\%), "Somewhat Helpful” (6.67\%).

Following the Summer School, we also found improvements in knowledge across all three of the main domains of learning - i.e. Technical, Behavioral and Business.

\section{[Fig. 3]}

On assessing the content of the summer school, students were asked "Overall, how engaging were the speakers at the summer school?". 26.67\% rated "Somewhat engaging," 26.67\% "Very Engaging" and 40.00\% "Extremely Engaging."

Students were asked to present a 5-minute pitch for the solution developed in collaboration with Ronan Smith and Kathy Ryan. The pitch was supposed to provide a short overview of the following aspects: Market assessment, State of the art, Technical Development, Healthcare Challenge, Evaluation and Business plan. The different groups of students developed $m$-health solutions on three types of challenges: smart configurable Reminder for person with dementia to manage daily living, mhealth for caregivers and $m$-health for social interaction. The pitch took into consideration the needs and suggestions of people with dementia to develop an innovative app / idea that was also technically and economically sustainable.

[Fig 4]

On the final day, each group presented their idea and received questions/ feedback from the faculty and specific questions from Ronan Smith and Kathy Ryan. Some students really wanted to develop the solution after the summer school keeping the working group.

[Fig 5] [Fig 6]

The methodological results and advice from Ronan Smith and Kathy Ryan during the Summer School could be summarized in this recent interview (2017), where the activist with dementia and Vice-Chair of the European Group of People with Dementia, Chris Roberts described what in his opinion the key elements for an effective participatory design and creation project:

Before the engagement activity, the person should receive a summary of who the organization is, what the subject is, an agenda as early as possible, an alphabetical list of acronyms and their meaning. [...] If there is anything specific that the organizer wants from the person with dementia, then be explicit before the person gets there, of course there may be also other questions or issues that may crop up during the meeting but at least to know what they think would be valuable to know or discuss from the perspective of the patient [...].

So, my key message would be, if you want to do this engagement process, don't just tick a box, get suitable candidates, spend a bit more of time. Involvement should never be a ticking the box thing. Also, it should be positive and beneficial for all involved: patients, supporters and the people organizing the engagement activity ${ }^{26}$. 


\section{Discussion/Conclusion}

The experience and positive feedback that we collected from the Summer School students confirmed our belief that a true personalized approach to eHealth and mHealth solutions can only emerge from a highly reflective and immersive appreciation of people's subjective accounts of their lived experience. To achieve this goal, all people involved in the process need to believe that people with dementia can bring to the table knowledge and competence equally as valuable as their own. Although this is widely accepted, our co-design experience indicates that it is only by allowing people with dementia to be involved as experts in their own rights that we can hope to create truly relevant and valuable technologies that reflect their real life needs and expectations.

As Dementia Alliance International's member and advocate with dementia Mike Belleville observed during his presentation at the Alzheimer's Disease International annual conference which took place in July 2018 in Chicago, when it comes to technology design the appreciation of diversity and individuality plays a much larger role than the traditional biomedical approach to dementia usually afford. People with dementia do vary according to the type of dementia and type of impairments; but even more importantly, people are different not only because of their condition but especially because they lead very different lives, according to who they were before and after they received their diagnosis, the values and expectations that shape their current worldviews, their lifestyle priorities, the level of family and community support they receive, and so on. In other words, what works for one person might not work for another person who lives with the same condition ${ }^{15}$.

Another crucial aspect to consider is that not everybody is keen on or interested in improving his or her quality of life by adopting an assistive technology. Some people may be variably resistant to using or adopting a new technology or have an ambivalent relationship with the technologies they use. Such ambivalence can easily escalate when a person lives with dementia. This was the case of Ronan Smith who described his relationship with technology in this way in his opening speech:

"Technology can confuse and mislead me, and if I am being honest I do not completely trust technology. When I travel I bring the laptop and the phone - I don't trust either item on its own! [...]. I feel I am being somewhat left behind with technology..."

And yet Ronan remained hopeful and envisioned a new generation of technologies that are truly empowering and enabling:

I believe technology could support remaining at work [...] Supportive technology coupled with good understanding would be a life changing combination! [...] the technology you design should be instinctive and reactive and most importantly individualised. Kathy and I both have Alzheimer's disease but we are different people. I hope you can create technology that supports not diminishes personhood.

Another aspect to consider is that not everybody is ready to be involved as a co- and be creative and behave accordingly ${ }^{6}$. Even the capacity to share one's knowledge and experience with others is not a given. Many people, especially if they live with stigmatized health or social conditions, need to feel safe and at ease to open up with others about the challenges they face in their everyday life as a consequence of their diagnoses. Kathy and Ronan proved to be invaluable experts, but their experience as national advocates and spokespeople, their ability for self-reflection on their own needs and expectations, as well as their ability for providing very precise indications to Summer School's 
participants, were in many ways exceptional. In light of their involvement, we suggest that researchers may find useful to involve people with dementia who are used to participate in support groups that empower them into sharing with others their everyday challenges and sensitive issues.

These are only a few of a wide constellation of variables and engaging factors that emerged during our 4 days of Summer School. These are also issues that can threaten the quality and outcome of a codesign project we fail to understand that our knowledge on what is needed and expected by a person with dementia is partial if not distorted by our tendency to reduce this illness to stereotypes that tend to reduce or disempower ${ }^{27,28}$.

In adopting a participatory approach to design, we were able to engage with the participants and develop an immersive relationship that improved their understanding of the lived experience with this condition and the unmet needs and expectations that people with dementia have in terms of technological support. Our approach contributes to further advance the case of including people with dementia in co-design activities as experts in their own right.

\section{Appendix}

Appendices may contain complementary information that was not integrated into the main text (tables, figures, and/or formulas). They may include references, which should be listed in the general reference list of the manuscript. However, tables and figures should be numbered separately.

\section{Supplementary Material}

Supplementary Material directly relevant but not essential to the conclusions of the paper may be submitted in separate files. Further information on Supplementary Material can be found in the Guidelines for Authors.

\section{Statements}

All papers must contain the following statements after the main body of the text and before the reference list:

\subsection{Acknowledgement}

NA

\subsection{Statement of Ethics}

The authors have no ethical conflicts to disclose.

\subsection{Disclosure Statement}

The authors have no conflicts of interest to declare.

\subsection{Funding Sources}

This article was developed within the activities of the Horizon2020 European REMIND project. The project has received funding from the European Union's Horizon 2020 research and innovation programme under the Marie Skłodowska Curie grant agreement No 734355. 


\subsection{Author Contributions}

In the Author Contributions section, a short statement detailing the contributions of each person named as an author should be included. If an author is removed from or added to the listed authors after submission, an explanation and a signed statement of agreement confirming the requested change are required from all the initially listed authors and from the author to be removed or added.

Contributors to the paper who do not fulfil the ICMJE Criteria for Authorship should be credited in the Acknowledgement section.

\section{References (Numerical)}

1. Rodgers PA. Co-designing with people living with dementia, CoDesign 2018, 14:3:188-202. DOI: $10.1080 / 15710882.2017 .1282527$

2. Treadaway C, Kenning G. Sensor e-textiles: person centered co-design for people with late stage dementia. Working with Older People. 2016.Vol. 20 (2):76-85. DOI: 10.1108/WWOP09-2015-0022

3. Hendriks N, Truyen F, Duval E. Designing with Dementia: Guidelines for Participatory Design together with Persons with Dementia. In: Kotzé P., Marsden G., Lindgaard G., Wesson J., Winckler M. (eds) Human-Computer Interaction - INTERACT 2013. INTERACT 2013. Lecture Notes in Computer Science, vol 8117. Springer, Berlin, Heidelberg

4. Tan L, Szebeko D. Co-designing for dementia: The Alzheimer 100 project. AMJ 2009.1 (12):185-198. DOI: 10.4066/AMJ.2009.97

5. Sanders EBN, Stappers P J. Probes, Toolkits and Prototypes: Three Approaches to Making in Codesigning. CoDesign 2014. 10 (1):5-14.

6. Sanders EBN, Stappers PJ. Co-creation and the new landscapes of design, Co-Design 2008. 4(1): 5-18, DOI: 10.1080/15710880701875068

7. Combs SD. Startling technologies promise to transform medicine. British Medical Journal. 2006;333(7582):1308-1311. [PMC free article] [PubMed]

8. Abras C, Maloney-Krichmar D, Preece J. User-Centered Design. In: Bainbridge W, editor. Encyclopedia of Human-Computer Interaction. 2004. Sage: Thousand Oaks

9. Gustafson DH, Hawkins RP, Boberg EW. Impact of a Patient-Centered, Computer-Based Health Information/Support System. American Journal of Preventive Medicine. 1999

10. Brennan PF. Telehealth: Bringing Health Care to the Point of Living. Medical Care 1999;37(2):115-116. [PubMed]

11. Brennan PF. Characterizing the Use of Heath Care Services Delivered via Computer Networks. Journal of the American Medical Informatics Association. 1995;2(3):160168. [PMC free article] [PubMed]

12. Roser T, DeFillippi R, Samson A. Managing your co-creation mix: co-creation ventures in distinctive contexts. European Business Review. 2013; 25(1): 20-41. https://doi.org/10.1108/09555341311287727

13. Kleinsmann M, Valkenburg R. Barriers and enablers for creating shared understanding in codesign projects. Design Studies. 2008 Jul; 29(4): 369-386.

14. Lindsay S, Brittain K, Jackson D, Ladha C, Ladha K, Olivier P. Empathy, participatory design and people with dementia. In Proc. SIGCHI Conference on Human Factors in Computing Systems (CHI '12). ACM, New York, NY, USA; 2012. 521-530. DOI: https://doi.org/10.1145/2207676.2207749

15. Dementia Alliance International [Internet]. Belleville M., Mulliken C. People with Dementia and Assistive Technologies [cited 2018 Sep 4]. Available from: https://www.dementiaallianceinternational.org/hello-my-name-is-mike-belleville/

16. Sifton CB. Well-being and doing: enabling occupation with persons with dementia. Alzheimer's Care Today. 2000 Apr 1;1(2):7-28. 
17. Keith, S. and Whitney, G. Bridging the gap between young designers and older users in an inclusive society. In Proc. The good, the bad and the challenging: the user and the future of ICT, (1998).

18. Brooker D. What is person-centred care in dementia?. Reviews in clinical gerontology. 2003 Aug;13(3):215-22.

19. Kitwood T. Dementia Reconsidered. Open University Press, 1997.

20. Dupuis SL, Gillies J, Carson J, Whyte C, Genoe R, Loiselle L, Sadler L. Moving beyond patient and client approaches: Mobilizing 'authentic partnerships' in dementia care, support and services. Dementia. 2012 Jul;11(4):427-52.

21. Clarke CL, Wilkinson H., Watson J, Wilcockson J, Kinnaird L, Williamson T. A Seat Around the Table: Participatory Data Analysis With People Living With Dementia. Qualitative Health Res. 2018 May; 28 (9):1421-1433. https://doi.org/10.1177/1049732318774768

22. Gove D, Diaz-Ponce A, Georges J, Moniz-Cook E, Mountain G, Chattat R, Øksnebjerg L, European Working Group of People with Dementia. Alzheimer Europe's position on involving people with dementia in research through PPI (patient and public involvement). Aging \& mental health. 2018 Jun 3;22(6):723-9.

23. Read ST, Toye C, Wynaden D. The participation of people with dementia in the planning of their care and support: An integrative literature review. Dementia. 2018 Jan 1:1471301218784806. DOI: https://doi.org/10.1177/1471301218784806.

24. Bennett B., McDonald F., Beattie E., Carney T., Freckelton I., Whitea B., Willmotta L.. Assistive technologies for people with dementia: ethical considerations. Bull World Health Organ 2017;95:749-755. doi: http://dx.doi.org/10.2471/BLT.16.187484

25. Jenkins, N. Dementia and the inter-embodied self. Soc Theory Health 2014; 12: 125. https://doi.org/10.1057/sth.2013.24

26. PARADIGM [Internet]. Roberts $C$. Patient engagement in dementia: extra support leads to informed contributions [cited 2017 Aug 27]. Available from: https://imi-paradigm.eu/patientengagement-in-cognitive-impairment-extra-support-leads-to-informed-contributions/

27. Rodgers P.A., Winton E. Breaking Well-Formed Opinions and Mindsets by Designing with People Living with Dementia. In: Langdon P., Lazar J., Heylighen A., Dong H. (eds) Breaking Down Barriers. CWUAAT 2018. Springer, Cham

28. Span M, Hettinga M, Vernooij-Dassen M, Eefsting J, Smits C. Involving people with dementia in the development of supportive IT applications: a systematic review. Ageing research reviews. 2013 Mar 1;12(2):535-51.

\section{Figure Legends}

Fig. 1. Summer School Program - Edition 2018

Fig. 2. Net promotor score in response to "How likely is it that you would recommend the Summer School to the colleague?"

Fig. 3. ESR rated their knowledge in each domain, technical, behavioral and business before and after the summer school

Fig 4. Example of a Summer School pitch outcome

Fig 5. Example of a Summer School Solution: technological architecture

Fig 6. Screenshot of the Remind app 